\title{
David Delgado Ramos. Problemas actuales del Derecho Parlamen- tario, Editorial Aranzadi, Cizur Menor (Navarra), 2018, 244 pp.
}

\author{
http://dx.doi.org/10.18543/ed-66(2)-2018pp501-507
}

1. La disposición que el autor presenta del marco jurídico-político de las relaciones Gobierno-Parlamento en nuestro régimen parlamentario se confirma de manera impecable en la obra, al asumir un encaje pragmático mediante un análisis novedoso de los acontecimientos acontecidos en estos últimos años. Entre ellos, la metamorfosis de los actos y funciones parlamentarios, al carecer los partidos políticos de mayoría parlamentaria amplia en las últimas elecciones generales. Originando, como así resalta el autor, el mayor período de Gobierno en funciones en los cuarenta años de vigencia constitucional.

Desde esta situación multipartidista en el Parlamento, el autor ofrece una visión esclarecedora de cuestiones trascendentales desde el punto de vista del derecho parlamentario, como: el control del Parlamento a un Gobierno que se encuentra en funciones, es decir, con el apoyo de la Cámara de la legislatura previa hasta la sucesiva legislatura; la práctica del «préstamo parlamentario» para poder formar Grupo, a partir del estudio de una discutible Sentencia del TC; y, por último, la congruencia o no del uso del veto presupuestario por parte del Gobierno.

Desde su trabajo, considera que las disconformidades manifestadas por el pasado Gobierno en funciones, entre otras, mediante la figura del veto presupuestario colaboran "como un eje central de la función de indirizzo politico del Gobierno y motor de su acción política», no obstante, recalca el «uso indebido del mismo con una vis expansiva». Por ende, en la relación Parlamento-Gobierno se ha producido «una evidente restricción de las funciones legislativas y de control del Parlamento». Cuestión distinta es la situación producida como consecuencia de la «larga interinidad gubernamental del Gobierno en funciones», en la que el Gobierno, en lugar de ser el garante del presupuesto en vigor mediante el freno de las iniciativas y enmiendas de contenido presupuestario, se encuentra cesado y carente de la confianza parlamentaria.

En el ámbito del veto presupuestario, pese a varias proposiciones de reforma del Reglamento del Congreso de los Diputados para fortalecer la posición del Parlamento, Delgado Ramos propone utilizar la no usada Oficina Presupuestaria. En cualquier caso, 
entiende que esta proposición debe ser tomada con cautela «toda vez que existen dudas constitucionales en torno al alcance de la limitación del veto presupuestario del Gobierno dada su intrínseca conexión con la función de indirizzo político».

En esta línea, también se subrayan otros hechos, como el hecho de que el Gobierno interpusiera contra el Parlamento un conflicto de atribuciones ante el Tribunal Constitucional, para no incluir en el orden de día y debatir unas iniciativas de la oposición parlamentaria. Igualmente el autor atiende a otra problemática recurrente desde los inicios de la democracia parlamentaria, en concreto, al préstamo de diputados y senadores en la constitución de los grupos parlamentarios, que supone una desvirtuación del sentido de la representación.

En el mismo prólogo, el profesor Vidal Prado reconoce la actualidad del problema y la visión crítica pero resolutiva del autor de la obra; asimismo, el rigor jurídico y práctico ante cuestiones que quieren dibujar una «nueva» política. Mencionado la situación política presente, donde hay ausencia de mayorías claras, o lo

El libro se articula en un prólogo, tres capítulos y un anexo jurisprudencial, por lo que la estructura es acorde a las cuestiones que se dirimen, a efectos explicativos esta agrupado en: el estudio del control parlamentario del Gobierno en funciones, haciendo hincapié en la XI Legislatura; posteriormente el "préstamo» parlamentario en la constitución de los grupos parlamentarios de las Cortes Generales, incluyendo un análisis a la STC 76/2017; $\mathrm{y}$, por último, el veto presupuestario del Gobierno, con especial estudio a la XI Legislatura. En suma, el empeño de Delgado Ramos, es una reflexión profunda, acerca del modelo de relaciones Gobierno-Parlamento.

2. En atención al control parlamentario del Gobierno en funciones, el autor inicia su exposición aludiendo a la más breve legislatura de la historia democrática, la XI Legislatura, origen del extenso Gobierno en funciones, y causa del debate en torno al posible control parlamentario del Gobierno en prorrogatio.

Se entiende que el Gobierno en funciones es una institución típica en las formas parlamentarias de gobierno, originado en circunstancias singulares y debido al principio de responsabilidad de las instituciones y de continuidad del Estado. Entre estas funciones primordiales del Gobierno en funciones, la doctrina destaca el elemento del despacho ordinario de los asuntos públicos, conocido como affaires courantes en Francia, o amministrazione ordinaria en Italia.

Pues bien, este Gobierno en prorrogatio «de honda limitación jurídica y fáctica», estaba en una situación extraña, al carecer «de la confianza parlamentaria del Congreso de los Diputados», y que «no debía someterse al control parlamentario de una Cámara que no le había otorgado su confianza». En contraposición, el poder legislativo, consideraba que el Gobierno «debía someterse a su control, dado que la situación de interinidad gubernamental no suspendía el ejercicio de la función de control». Esta confrontación conllevó un conflicto de atribuciones ante el TC, que sigue sin resolución. Ciertamente, por 
un lado, al estar en funciones el Gobierno, entendía que al no poseer la competencia para fijar la orientación política, carecía de sentido de control parlamentario; al tener limitada su actuación al despacho ordinario. En contraposición, por otro lado, el Parlamento comprendía que no podía exigir responsabilidad política, pero sí, la función de control.

El autor, examinando el alcance y consecuencias del control parlamentario, comienza por el marco jurídico del Gobierno en funciones. Ahí, entiende que el Gobierno cesante "está sometido a una fuerte limitación en su actuación», al carecer de relación fiduciaria con quien legitima su razón de ser.

Otro punto destacable es que el control parlamentario en la situación jurídico-política del Gobierno en funciones carece de regulación constitucional, por lo que fue la legislación ordinaria quien articuló y delimitó las competencias de ese Gobierno en dos: facilitar el traspaso de poderes al nuevo Gobierno y el despacho ordinario de los asuntos públicos. De este modo, el constituyente no mencionó nada acerca de las atribuciones del gobierno en sus funciones, y peor aún, sus límites. Tuvo que ser el legislador ordinario el que concretase las limitaciones, recogidas en el art. 21.3 de la Ley de Gobierno, entre las que se puede clasificar: a) facilitar el normal desarrollo del nuevo Gobierno y el traspaso de poderes; b) gestión al despacho ordinario de los asuntos públicos y c) casos de urgencia debidamente acreditados o por razones de interés general puede adoptar medidas.

La función de traspaso de poderes es una función plausible y propia de la cultura institucional democrática de lealtad institucional. En cambio, la fórmula de limitar la gestión al despacho ordinario de los asuntos públicos, es un concepto ambiguo que obliga a discernir que es despacho ordinario, aunque mucho más ambigua resulta la invocación de razones de interés general cuya acreditación así lo justifique. En este punto, es donde la relación del Parlamento hacia el Gobierno en prorrogatio podría producir mayores choques, si el Gobierno se excede de forma notoria.

Atendiendo a los hechos acontecidos que presenta el autor, la gran cuestión de alcance suscitada es el pendiente pronunciamiento del control parlamentario del Gobierno en funciones, en concreto la negativa del entonces Gobierno en funciones someterse a las distintas fórmulas de control parlamentario, que suscitó el aún no resuelto conflicto entre órganos constitucionales en el Tribunal Constitucional.Para el autor, el control parlamentario resulta imprescindible por la «naturaleza fiduciaria entre Gobierno y Parlamento que constituye el eje sobre el que pivota la legitimidad política en la democracia», aunque reconoce, también que la ausencia de alguna o algunas de estas figuras «no presupone la inexistencia de dicho control al Ejecutivo».

En conclusión, Delgado considera que «la situación de interinidad gubernamental no excluye en absoluto, el control político ejercido por la Cámara, que no puede verse "coartado». Las previsiones constitucionales no justifican la cesación de la función de control, antes al contrario. Ahora bien, no puede ser ejercido "en sentido 
amplio sino que, habida cuenta de las propias limitaciones legales establecidas por la Ley de Gobierno, debe amoldarse a las muy acotadas funciones que puede ejercer el Ejecutivo». En suma, es un control restringido, en el sentido de circunscrito a la función ordinaria y de trámite del despacho ordinario de los asuntos públicos, lo que exige un análisis particular. Por ello, le parece lógico que a «un Gobierno limitado le corresponde, naturalmente, un control limitado», aunque «la ausencia de relación fiduciaria entre el Ejecutivo cesante y la nueva Cámara surgida de las elecciones no puede suprimir la función del control parlamentario, sólo restringirlo a las limitaciones funcionales y competenciales que la ley establece para el Gobierno en funciones, adaptando el control político parlamentario al marco jurídico del Gobierno».

3. En lo concerniente al préstamo de parlamentarios en la constitución de los Grupos Parlamentarios de las Cortes Generales, el profesor Delgado considera que constituye una práctica parlamentaria que ha derivado en un auténtico fraude de ley, justificable para los grupos por las sustanciales ventajas políticas y materiales que supone.

En ese sentido, y aunque analiza prolijamente todos los precedentes parlamentarios, se centra especialmente en la XII Legislatura, con la negativa de la Mesa del Senado a no respaldar la constitución del Grupo Parlamentario Catalán (CDC), sosteniendo que no cumplía los requisitos del Reglamento del Senado, pese a que contaban con cuatro senadores y lograron otros seis senadores para alcanzar los diez exigidos reglamentariamente para poder constituirse en grupo.

Para el autor, pesa a la aparente claridad de los requisitos formales y materiales de los arts. 23 y 24 del Reglamento del CD, no ha supuesto obstáculo para sortearlos «bien sea por vía del cociente nacional del cinco por ciento, o bien por medio de la representatividad territorial en determinadas circunscripciones aunque, en la práctica, su aplicación no haya sido especialmente problemática».

Por otro lado, entre las variaciones al préstamo de senadores, la introducción de la cifra mínima de seis senadores para ser grupo introduce dos notas señaladas por el autor: «el umbral mínimo es fijo, no variable, lo cual exige siempre el mismo número de senadores a prestar, -cuatro-», $\mathrm{y}$ "debe existir una identidad del grupo común bajo la cual se engloban los senadores».

Por ello, a pesar de que la STC 76/2017 determine su plena constitucionalidad, ello no evita que deba reconsiderarse la necesidad de interpretarsistemáticamentey teleológicamente el espíritu de la norma, puesto que saltándose los criterios cuantitativos exigidos se estaban formando grupos mediante el préstamo parlamentarios, produciéndose, en expresión del autor, una subversión de «la representación al disociar de forma manifiesta la representatividad electoral obtenida con la representatividad parlamentaria expresada en la Cámara».

En ese sentido, el autor propone una modificación del art.23.1 Reglamento del CD y del art. 27.1 del RS, con este planteamiento: a) reduciendo el número de diputados exigidos - aunque considera que conllevaría 
una fragmentación excesiva del arco parlamentario-; b) evitando la adscripción temporal de diputados que irían al Grupo Mixto, a un grupo parlamentario en formación -con lo que se evitaría la sobrerrepresentación de formaciones políticas y aumentaría la del Grupo Mixto-; c) y, por último, mediante una modificación normativa que establezca que un parlamentario proveniente de una candidatura mayoritaria que se asocia a un grupo distinto en el momento de darse de baja, no pueda en toda la legislatura ser adscrito más que al Grupo Mixto -lo que alteraría el estado de fuerzas-.

5. Al tratar el mecanismo del veto presupuestario, entiende que la naturaleza de la Ley de Presupuestos Generales del Estado reviste un especial carácter político, además de estar relacionada -como eje central- con la función del indirizzo político del Gobierno. Así, el mecanismo constitucional del art.134.6 $\mathrm{CE}$, es decir, el veto presupuestario, colabora a este fin en defensa de la integridad del presupuesto aprobado, limitando el control del Parlamento.

En esta línea, ha de reconocerse el uso indebido que se ha hecho del mismo con una vis expansiva, por parte del Ejecutivo, ya que ha producido clarividentes restricciones a las funciones legislativas y de control del Parlamento, que se suma a los conflictos antes reseñados en el ámbito de las relaciones Gobierno-Parlamento, y que se ha podido observar en este período de interinidad gubernamental del Gobierno en funciones.

Así, se ha manifestado con mayor incidencia el choque en las relaciones Gobierno-Parlamento, pese a que en su origen fue diseñado para evitar ese tipo de confrontaciones. La naturaleza del Presupuesto, debido a su configuración anual y ductilidad normativa, se concibe para equilibrar los poderes, dado que la competencia en la elaboración y ejecución corresponde al Ejecutivo, mientras que la aprobación y control al Legislativo (responsabilidad desdoblada, según la STC 27/1981 de 20 de julio). Con ello, permite definir las políticas de gasto público al Gobierno; y por la otra, favorece una implicación especial del Parlamento.

Precisamente por ello, la importancia radica en el impacto político-económico de cualquier alteración en su articulado, ya que puede constituir un cambio en la estabilidad presupuestaria y sostenibilidad financiera del país, y funda el sentido del veto presupuestario del Gobierno a la tramitación de iniciativas del Parlamento, siempre que suponga un aumento de créditos o disminución de ingresos presupuestarios, como un mecanismo de defensa -sistema de contrapesos, favorable al Ejecutivo-. Ahora bien, como reconoce el autor, a sensu contrario, no «puede vetar su tramitación cuando implique una reducción de créditos o incremento de ingresos».

Por lo tanto, la potestad gubernamental parece resultar infinita, puesto que los órganos de gobierno de la Cámara carecen de réplica ante la negativa de tramitación por parte del Ejecutivo. Algo que, indirectamente, produce una esfera de aplicación vis expansiva del veto, a cualquier iniciativa de incidencia al impacto financiero. En el fondo, sólo hay un decisor, ese es el Gobierno. Ahora bien, como apunta el autor, esa potestad del Gobierno, debe ser justificada, en el sentido de razonar su negativa. 
Por estos motivos, Delgado Ramos considera que con este criterio de oportunidad política, mediante el veto, ha limitado a las Cortes «en su triple vertiente funcional: presupuestaria, legislativa y de control».

Respecto al veto, que motivaría la interposición de un conflicto de atribuciones ante el TC, sucedieron los siguientes hechos concretos: el Ejecutivo rechazó la tramitación de numerosas proposiciones de ley presentadas por los grupos de la oposición, asimismo a varias asambleas legislativas de las CCAA, haciendo uso de su facultad de veto presupuestario. Debido a ello, la Mesa del Congreso, tras el examen de dichas negativas de conformidad por parte del Gobierno, consideró que la proposición para mejorar la condición de subcontratados y la proposición educativa, resultaban injustificadas. Al respecto, el Gobierno, al constatar la voluntad del Congreso de no aceptar la negativa de conformidad a la tramitación de las mencionadas proposiciones, fue agotando el procedimiento, antes del sucesivo recurso ante el TC por un conflicto de atribuciones.

Debido a que se exige el consentimiento del Gobierno con carácter general, para la tramitación de todas las enmiendas o proposiciones de ley que supongan aumento de los créditos o disminución de los ingresos presupuestarios, son los Reglamentos de las Cámaras los que velan por el trámite legislativo del veto. En concreto, en el Congreso de los Diputados, a diferencia del Senado, se establece un procedimiento diferenciado, según se trate de proposiciones o enmiendas. Si se trata de proposiciones, según el art.126.2 del Reglamento, la Mesa de la Cámara será el órgano encargado de enviar al Ejecutivo todas las proposiciones presentadas. Por el contrario, si se trata de enmiendas, como regula el art.111.2 del Reglamento, será la Ponencia de la Comisión la encargada de redactar el informe por conducto del Presidente del Congreso, siendo la que remita aquellas enmiendas a un proyecto de ley que supongan aumento de los créditos o disminución de los ingresos presupuestarios (art.111.1).

Igualmente, han merecido un análisis exhaustivo por el autor las SSTC $223 / 2006$ y $242 / 2006$, que resolvían recursos de inconstitucionalidad en los que el conflicto entre Gobierno-Parlamento a causa del veto. Aquí, el autor, junto a la mayor parte de la doctrina, considera el veto presupuestario como una característica definitoria del parlamentarismo racionalizado que garantiza la dirección y ejecución por parte del Gobierno. Observando la doctrina constitucional, en concreto, la STC $223 / 2006$, que se suscita en un recurso de inconstitucionalidad interpuesto por el Gobierno de Extremadura y por senadores del Grupo Socialista contra una reforma del Reglamento de la Asamblea de Extremadura que incidía en la tramitación de proposiciones de ley con alcance presupuestario. Pues bien, la solución ofrecida de la reforma que se proponía, consistía en la atribución a la Mesa, una función de filtro previo, ante posibles discrepancias con las decisiones del Gobierno, dejando en última instancia la decisión al Pleno de la Cámara. En la referida Sentencia se declara inconstitucional la reforma operada, al suponer una vulneración de las competencias atribuidas a la Junta mediante su Estatuto de Autonomía. 
Similar caso, aunque dispar solución, depara la STC 242/2006, debido un recurso interpuesto por el Grupo Parlamentario Popular en el Parlamento Vasco por el hecho de inadmitir a trámite la proposición de ley sobre la modificación de un artículo del régimen presupuestario. En primer lugar, la Mesa admite a trámite la proposición, pero tras recibir el criterio del Gobierno respecto de la toma en consideración, adoptó un nuevo acuerdo gracias al voto de calidad del Presidente, no admitiéndolo a trámite. La cuestión que alegaban los recurrentes era el ámbito temporal indeterminado, al considerar que la decisión inadmitida no estaba fundamentada, debido a que la proposición de ley afectaba a ejercicios presupuestarios futuros. Así, el TC entendió en su pronunciamiento que la Mesa del Parlamento vasco sí tenía margen de decisión y control frente al veto, en especial a su interpretación sobre cuándo producirá el impacto.

En esta línea Delgado Ramos propone una propuesta de reforma, acotando el veto presupuestario del Gobierno con cautela, "utilizando para ello la Oficina Presupuestaria de las Cortes Generales -en vigor, pero no en funcionamiento-, que ejercería, en consonancia con lo establecido en su ley de creación, para el "asesoramiento técnico en materia de seguimiento y control de la ejecución de los Presupuestos Generales del Estado"».

6. En conclusión, el autor, en esta interesantísima obra sobre los «Problemas actuales del Derecho parlamentario», el autor ha puesto de relieve algunos dilemas trascendentales de los sistemas parlamentarios racionalizados. Sabemos que los sistemas constitucionales se edifican sobre el principio de separación de poderes, aunque quizás fuese más idóneo hablar de división de funciones. El motivo de esta separación, como es conocido, radica en evitar la excesiva concentración de poder en un órgano determinado. En los sistemas parlamentarios, el Ejecutivo emana del Legislativo, a cambio de controlar su actuación. En esta línea de parlamentarismo racionalizado, existen en nuestro ordenamiento, mecanismos para que cada uno desarrolle de forma adecuada sus funciones constitucionalmente asignadas y evite situaciones de vacíos de poder o haga inviable la gobernabilidad.

Pues bien, en dos de los tres casos reseñados por el autor, -el control parlamentario del Gobierno en funciones y el veto presupuestario del Gobierno-, se ha producido un «choque de trenes») político entre ambas Cámaras, que ha supuesto la interposición de un conflicto entre órganos constitucionales ante el Tribunal Constitucional. Conflictos que podrían ser resueltos, como propone el autor, con sendas modificaciones normativas que contribuyesen a perfilar y limitar ambos institutos.

Por último, en relación con el préstamo de parlamentarios, y pese a la sentencia del TC, la praxis ha devenido en una fraudulenta costumbre que en nada contribuye a mejorar la calidad de la representación parlamentaria y, por ende, la democracia.

Amir Al Hasani Maturano

(Universidad de las Islas Baleares) 


\title{
David Delgado Ramos. Problemas actuales del Derecho Parlamen- tario, Editorial Aranzadi, Cizur Menor (Navarra), 2018, 244 pp.
}

\author{
http://dx.doi.org/10.18543/ed-66(2)-2018pp501-507
}

\section{Copyright}

Estudios de Deusto es una revista de acceso abierto, lo que significa que es de libre acceso en su integridad. Se permite su lectura, la búsqueda, descarga, distribución y reutilización legal en cualquier tipo de soporte sólo para fines no comerciales, sin la previa autorización del editor o el autor, siempre que la obra original sea debidamente citada y cualquier cambio en el original esté claramente indicado 